Psychological Medicine 2000, 30, 489-490. Printed in the United Kingdom

(C) 2000 Cambridge University Press

EDITORIAL

\title{
Not an age of depression after all? Incidence rates may be stable over time ${ }^{1}$
}

In an important paper in this issue Murphy et al. (pp. 503-512) report on incidence rates for depression over 40 years in the Stirling County Study. Incidence rates remained stable, contrary to most evidence that is principally based on prevalence or retrospective lifetime prevalence. Incidence rates were only a little higher in women than in men.

Incidence rates are assuming increasing importance in psychiatry as they do in other areas of epidemiology. Prevalence rates are complex, depending not only on incidence of new cases of the disorder, but its persistence, and in a recurrent disorder, recurrence. Incidence rates are unbiased by these factors, a particularly valuable attribute when considering risk factors. In depression, development and widespread use of antidepressants, newer patterns of care, and in the opposite direction, increased urbanization with its accompanying social pressures, could have produced considerable changes in outcome in the last 40 years. Changes in enumerated prevalences alone could reflect changed length of episodes and rates of recurrence, so giving a misleading picture as to what has happened to the disorder.

The Stirling County Study is one of the classics of epidemiology. Its originator, Alexander Leighton, is an author of the present paper with his wife, Jane Murphy, who has directed the study since the mid-1970s. Representative community samples were studied cross-sectionally in 1952 , 1969 and 1992, and the previously studied samples restudied on follow-up at the later points. The design enables a separation of period effects, involving all subjects at one time point, from cohort effects. In this study similar temporal stability of prevalence has been found (Murphy et al. 2000 b) to that now reported for incidence.

There are also some puzzles in this study. Contrary to most reports, prevalences on the main case finding instrument were approximately equal in women and men, although using a different instrument, the Diagnostic Interview Schedule, which contains more items, there was a female predominance (Murphy et al. pp. 503-512). Chronicity changed only a little (towards more chronicity in the more recent cohort), but prevalence increased in younger women.

Suspicions that depression was becoming more common arose in the 1960s and 1970s, as high prevalence rates were found in the general population. Sometimes these have been linked to speculations about the stress of modern life compared with earlier times, a sentimental view that finds little support in photographs of poverty in working class areas of large cities in the late nineteenth century and start of this century. The early data were reinforced by findings from the important US Epidemiologic Catchment Area study (Robins \& Regier, 1991), which found higher lifetime rates in younger subjects than expected from the lifetime rates reported by older subjects, suggesting a cohort effect (Klerman \& Weissman, 1989). Studies from other countries (CrossNational Collaborative Group, 1992) have given similar findings.

Studies employing a single retrospective interview to establish lifetime prevalence have one problem. They depend on retrospective recall, and if older people tend to forget the travails of their youth, artefactual findings can arise. This is a plausible hypothesis, but, so far, not much tested directly in epidemiological case finding instruments. Recently, Andrews et al. (1999), in a 25 year

1 Address for correspondence: Professor E. S. Paykel, University of Cambridge, Department of Psychiatry, Addenbrooke's Hospital (Box 189), Cambridge CB2 2QQ. 
follow-up of depressives who had been hospitalized at the index episode, found that $70 \%$ could recall being depressed but only $50 \%$ could recall detailed symptoms sufficiently to satisfy diagnostic criteria. Lifetime rates for disorder in studies that retrospectively assess lifetime prevalence tend to be around twice the 6-month prevalences, which could indicate forgetting, although it could also indicate that a high proportion of disorder is chronic (Parker, 1987). In the long run, studies of successive cohorts and at successive periods are required to establish changes in rates.

One other major study has adopted a comparable successive cohort design. The Swedish Lundby Study was begun by Essen-Möller (Hagnell et al. 1982, 1990; Rorsman et al. 1990). Like Stirling County a disguised name, the area was initially rural and over time has undergone some urbanization. The study involved two cohorts, first studied cross-sectionally in 1947 and 1957 respectively, with follow-up of the first cohort also in 1957, and of both in 1975. The conclusions in this study have been different. In Lundby incidence rates rose in the younger cohort and over time in the older cohort, and the gender ratio was approximately $2: 1$. It was findings from the Lundby study published in this journal (Hagnell et al. 1982) that provided the first good evidence of rising incidence.

However, in a Finnish study of samples from two contrasting communities followed up after 5 and 16 years, overall prevalence rates of disorder did not change, and the youngest birth cohort appeared to have lower rather than higher rates (Lehtinen et al. 1991). In a different kind of analysis employing structural equation modelling on data from a 13 year follow-up of the Baltimore ECA sample, Gallo et al. (1999) found less reporting of depressive symptoms in subjects aged over 65 who had been under 65 at the first wave, arguing against a cohort effect rather than an effect of age, or a period effect.

These studies are very difficult to carry out, requiring remarkable persistence and devotion. Over time methods change, instruments are superseded, diagnostic criteria and usage may change in subtle ways, samples alter in characteristics and accessibility for study. Statistical power may be limited. The very large epidemiological samples possible in multi-centre studies today were not feasible 40 to 50 years ago.

No study stands by itself without replication, and further studies of this kind are still needed, to sort out what is happening. The Stirling County authors discuss possible reasons for discrepancies between studies. This paper from a monumental study challenges some recent assumptions. We are pleased to publish it as a major contribution.

\section{REFERENCES}

Andrews, G., Asntey, K., Brodaty, H., Issakidis, C. \& Luscombe, G. (1999). Recall of depressive episode 25 years previously. Psychological Medicine 29, 787-791.

Cross-National Collaborative Group (1992). The changing rate of major depression: cross-national comparisons. Journal of the American Medical Association 268, 3098-3105.

Gallo, J. J., Rabins, P. V. \& Anthony, J. C. (1999). Sadness in older persons: a 13-year follow-up of a community sample in Baltimore, Maryland. Psychological Medicine 29, 341-350.

Hagnell, O., Lanke, J., Rorsman, B. \& Öjesjö, L. (1982). Are we entering an age of melancholy? Depressive illnesses in a prospective epidemiological study over 25 years: the Lundby Study, Sweden. Psychological Medicine 12, 279-289.

Hagnell, O., Essen-Möller, E., Lanke, J., Öjesjö, L. \& Rorsman, B (1990). The Incidence of Mental Illness over a Quarter of a Century. the Lundby Longitudinal Study of Mental Illnesses in a Total Population Based on 42,000 Observation Years. Almqvist \& Wiksell: Stockholm.

Klerman, G. L. \& Weissman, M. M. (1989). Increasing rates of depression. Journal of the American Medical Association 261, 2229-2235.
Lehtinen, V., Lindholm, T., Veijola, J., Väisänen, E. \& Puukka, P. (1991). Stability of prevalences of mental disorders in a normal population cohort followed for 16 years. Social Psychiatry and Psychiatric Epidemiology 26, 40-46.

Murphy, J. M., Laird, N. M., Monson, R. R., Sobol, A. M. \& Leighton, A. H. (2000a). Incidence of depression in the Stirling County Study: historical and comparative perspectives. Psychological Medicine 30, 503-512.

Murphy, J. M., Laird, N. M., Monson, R. R., Sobol, A. M. \& Leighton, A. H. (2000b). A forty year perspective on the prevalence of depression from the Stirling County Study. Archives of General Psychiatry 57, 209-215.

Parker, G. (1987). Are the lifetime prevalence estimates in the ECA study accurate? Psychological Medicine 17, 275-282.

Robins, L. N. \& Regier, D. A. (eds) (1991). Psychiatric Disorders in America: The Epidemiologic Catchment Area Study. Free Press: New York.

Rorsman, B., Gräsbeck, A., Hagnell, O., Lanke, J., Öhman, R., Öjesjö, L. \& Otterbeck, L. (1990). A prospective study of firstincidence depression: the Lundby Study, 1957-1972. British Journal of Psychiatry 156, 336-342. 